\title{
CONTRASTING EFFECTS OF 4-WEEK INHALATION EXPOSURE TO PSEUDOCUMENE OR HEMIMELLITENE ON SENSITIVITY TO AMPHETAMINE AND PROPENSITY TO AMPHETAMINE SENSITIZATION IN THE RAT
}

\section{PIOTR LUTZ, SŁAWOMIR GRALEWICZ, DOROTA WIADERNA, RADOSŁAW ŚWIERCZ, ZOFIA GRZELIŃSKA, and WANDA MAJCHEREK}

Nofer Institute of Occupational Medicine, Łódź, Poland

Department of Toxicology and Carcinogenesis

\begin{abstract}
Objectives: Some data suggest that increased behavioural sensitivity to psychostimulants may develop after exposure to volatile chemicals in common use. The purpose of the present experiment was to find out whether and in what way inhalation exposure to pseudocumene (PS) or hemimellitene (HM) at low concentrations alters behavioural sensitivity to the psychostimulant amphetamine (AMPH), and propensity to develop behavioural sensitization to AMPH. Material and Methods: Adult male Wistar rats were exposed $6 \mathrm{~h} /$ day, 5 days a week for 4 weeks to PS or HEM at 0, 25, 100 or 250 ppm. Behavioural sensitivity to AMPH was assessed by measuring locomotor activity of the animals in an open-field. Behavioural sensitization to AMPH was induced by a repeated AMPH treatment. Results: In rats exposed to HEM, the behavioural sensitivity to AMPH was increased, but remained unchanged in rats exposed to PS. The second testing revealed an augmented behavioural response to AMPH in control rats. In the HM exposed rats this augmenting was significantly more evident and in the PS exposed rats significantly less evident than in controls. For each of the two solvents, the concentration-effect relationship was nonlinear; out of the three concentrations used, $100 \mathrm{ppm}$ was the most effective. Conclusions: The results confirm that low-level inhalation exposure to trimethylbenzene isomers may induce behavioural sensitisation and/or increase the susceptibility of the animals to develop this state upon repeated psychostimulant treatment. They show, however, that HM and PS differ markedly in their ability to induce such alterations.
\end{abstract}

Key words:

Hemimellitene, Pseudocumene, Inhalation exposure, Behavioural sensitization, Amphetamine, Rat

\section{INTRODUCTION}

Overuse of psychoactive substances, leading to dependence and addiction, is nowadays one of the grave social and medical problems in many countries. Therefore, pointing out factors increasing the subject's propensity for drug abuse and development of drug dependence and addiction becomes an important task. According to some authors, the development of drug dependence and drug addiction is strongly related to a state of sensitisation in the central nervous system (CNS) induced by an exposure and resulting in long-term enhancement of behavioural and neurochemical responses to various stressors [1-3]. If so, then factors with the sensitising potential are $-e x$ definitione - promoters of drug abuse and development of addiction. The best known sensitizers include psychostimulants (amphetamines and cocaine) and opiates. Sensitisation, however, may be induced also by various psychical and physical stressors [4], as well as exposure to some

Received: November 24, 2009. Accepted: February 12, 2010.

Address reprint request to P. Lutz, Department of Toxicology and Carcinogenesis, Toxicity Assement Laboratory, Nofer Institute of Occupational Medicine, św. Teresy 8, 91-348 Łódź, Poland (e-mail: astra@imp.lodz.pl). 
chemicals, which may be present in workplace, communal environment and at home [5-7]. The latter group includes also solvents (mainly aromatic hydrocarbons) which are extensively used as components of paints, lacquers and motor fuels [8-10]. Owing to physical and chemical properties and the biological activity - stimulant-like and narcotic effects - some solvents are used for entertainment which - like the use of psychostimulants and opiates leads to dependence and addiction [11-13]. Occupational or household solvent exposures are usually too low for inducing narcotic or psychostimulant effect. It would not be reasonable to exclude, however, that repeated exposures even at concentrations which may occasionally take place in occupational settings or during household use may lead to sensitisation. Results of laboratory studies on animals indicate that the dopaminergic system, i.e. the system which plays a key role in sensitisation and drug dependencies [14] is particularly vulnerable to solvents $[15,16]$. It has also been shown in several studies that inhalation exposure to toluene (methylbenzene) at concentrations close to the currently valid hygienic standards results in hypersensitivity to dopaminergic agonists [8,9]. Toluene is one of the most extensively used solvents. It is also most frequently abused by "sniffers" for entertainment $[11,17]$. The above explains why the focus has been mainly on this solvent. It is quite likely, however, that also other solvents may share its sensitising properties. So far, however, there is no accessible data on the sensitizing potential of other popular solvents.

Trimethylbenzene (TMB) is a component of solvent mixtures used in the paint and lacquer industry. In some petroleum products (e.g. Solvesso 100 - ExxonMobil Chemical, Belgium, Shellsol A - Shell Netherland Chemie B.V. Netherlands), the joint contribution of the three TMB isomers: pseudocumene (1,2,4-trimethylbenzene - PS), hemimellitene (1,2,3-trimethylbenzene - HM) and mesitylene (1,3,5-trimethylbenzene - MES), may exceed 40\%. It is also a substantial constituent of fuels [18], which means that the probability of a sporadic exposure to TMB is quite high. In the USA, the ACGIH hygienic standard for TMB has been set at $125 \mathrm{mg} / \mathrm{m}^{3}$ or $25 \mathrm{ppm}$ [19]. In Poland, the adopted MAC value for TMBs is $100 \mathrm{mg} / \mathrm{m}^{3}$ or $20 \mathrm{ppm}$, i.e. the same as for toluene [20]. Some years ago in studies on rats we found that a subchronic (4-week) inhalation exposure to PS or HM at 25, 100 and 250 ppm resulted in long-lasting changes in behaviour [21,22]. The character of these changes, i.e. an increased motoric response in situations of threat, suggested behavioural sensitisation. It has been shown years ago that behavioural sensitisation to stressful stimuli goes along with behavioural sensitization to amphetamine [23]. Amphetamine(s) (AMPH) is a psychostimulant and one of the most popular, especially among youngsters, neuroactive drugs. The purpose of the present work was to find out whether an inhalation exposure to TMB at the same concentrations as used in the previous study would result in an increased behavioural sensitivity to psychostimulant and/or increased propensity to develop hypersensitivity to psychostimulants after a psychostimulant exposure.

\section{MATERIALS AND METHODS}

\section{Chemicals}

Pseudocumene (1,2,4-trimethylbenzene), CAS no 95-63-6, and hemimellitene (1,2,3-trimethylbenzene), CAS no 52673-8, purity 97\%, were purchased from FLUKA.

Amphetamine (amphetamine sulphate - AMPH) was purchased from SIGMA. Before use, AMPH was solved in sterile physiological saline (Natrium chloratum 0.9\%) to the required concentration. It was administered intraperitoneally at $1.0 \mathrm{ml} / \mathrm{kg}$ b.w.

\section{Animals}

Adult male Wistar rats from an outbreed stock were used in the experiment. The animals were obtained from NIOM breeding farm. They were housed in group cages, 4 animals per cage, in standard laboratory conditions. The ambient temperature $\left(22^{\circ} \mathrm{C} \pm 0.5^{\circ} \mathrm{C}\right)$, humidity $(50-60 \%)$, and the light/dark cycle (12/12 $\mathrm{h}$ with the light on from 06:00 to $18: 00 \mathrm{~h}$ ) were automatically controlled. Solid food (Murigran pellets from AGROPOL, Motycz, Poland) and tap water were accessible in housing cages ad libitum. Body weight was measured routinely once a week. At the start of the experiment, the rats were about 3 months old and 
weighted $310-350 \mathrm{~g}$. Behavioural tests were performed between 09:00 and 15:00 $\mathrm{h}$.

Based on the body weight measurements, the animals were separated into seven groups ( $n=6-8$ animals per group):

1. Control - animals placed in the inhalation chambers and exposed to pure air,

2. PS25 - rats exposed to pseudocumene at $25 \mathrm{ppm}$,

3. PS100 - rats exposed to pseudocumene at $100 \mathrm{ppm}$,

4. PS250 - rats exposed to pseudocumene at $250 \mathrm{ppm}$,

5. HM25 - rats exposed to hemimellitene at $25 \mathrm{ppm}$,

6. HM100 - rats exposed to hemimellitene at $100 \mathrm{ppm}$,

7. HM250 - rats exposed to hemimellitene at $250 \mathrm{ppm}$. The study design was approved by the Local Ethics Committee in Łódź (Decision No: 36/ŁB/373/2007, Issue date: 2007-05-28).

\section{Inhalation exposure}

The rats were exposed to the trimethylbenzenes in $0.25 \mathrm{~m}^{3}$ inhalation chambers with forced constant airflow (15-16 air exchanges per hour). The input air was filtered and conditioned to a mean temperature of $22-24^{\circ} \mathrm{C}$. The required solvent vapour concentration was attained by bubbling an additional airflow through a flask containing solvent at $70^{\circ} \mathrm{C}$. Samples of chamber air were taken at $30 \mathrm{~min}$ intervals to monitor the exposure concentration. The animals were exposed $6 \mathrm{~h} /$ day from 8:00 to 14:00, five days a week for 4 weeks. Within the inhalation chambers they were located in wire-mesh cages with no sawdust. Water and food were not accessible during the exposure.

\section{The behavioural testing (pharmacological challenge test)}

The pharmacological challenge test used in the present experiment consisted in measuring motoric behaviour in an open field before and after intraperitoneal administration of amphetamine test dose $(0.5 \mathrm{mg} / \mathrm{kg})$. This testing was performed twice. The first testing (Session 1) was performed two weeks after the last exposure in the inhalation chambers. Afterwards the rats were subjected to a sensitisation procedure, which consisted of repeated i.p. administration of AMPH at $2.5 \mathrm{mg} / \mathrm{kg}$ b.w. (one injection per day for five consecutive days). The second testing in the open field (Session 2) was performed three weeks after the last sensitising dose of AMPH.

\section{Apparatus}

A computerized 4-unit set of activity cages (PORFEXLtd., Białystok, Poland) was used. Each cage $(63 \times 63 \times 40 \mathrm{~cm})$ was equipped with 2 tiers of infrared motion sensors allowing to measure locomotor (travelled distance) and exploratory (rearing) activities. Detailed description of the apparatus have been presented in other reports from this laboratory [24].

\section{Testing procedure}

Each testing (session 1 and 2) consisted of a preinjection measurement and two postinjection measurements, of which the first was preceded by injecting the rat with $0.9 \% \mathrm{NaCl}$ (postSAL measurement) and the second by injecting the rat with $0.5 \mathrm{mg} / \mathrm{kg}$ of AMPH (postAMPH measurement) dissolved in $0.9 \% \mathrm{NaCl}$. All solutions were prepared immediately before use and given intraperitoneally (i.p.) at $1.0 \mathrm{ml} / \mathrm{kg}$ volume. The preinjection and postSAL measurements lasted $30 \mathrm{~min}$ each. The postAMPH measurement lasted $120 \mathrm{~min}$. The interval between successive measurements was no longer than $2-5 \mathrm{~min}$. The postinjection measurements started immediately after the injections. The sensitisation induction was started one day after end of session 1 . For this purpose each rat was repeatedly injected with AMPH at $2.5 \mathrm{mg} / \mathrm{kg}$ b.w. (one injection/ day for five days). Session 2 was performed on day 21 after the last sensitising AMPH dose. The procedure employed in session 2 was exactly the same as in session 1 .

\section{Statistics}

For comparison purposes, the 120 min postAMPH measurement was divided into four $30 \mathrm{~min}$ sections. Thus, each testing (session) comprised six measurements of equal duration (30 min) denoted as „blocks”: 1 - preinjection block, 2 - postSAL block (i.e. after injection with $0.9 \% \mathrm{NaCl}$ ), and 3, 4, 5 and $6-$ successive postAMPH blocks (i.e. after injection with $0.5 \mathrm{mg} / \mathrm{kg}$ of AMPH). Such arrangement allowed for a better assessment of the dynamics of the AMPH effect (the effect 


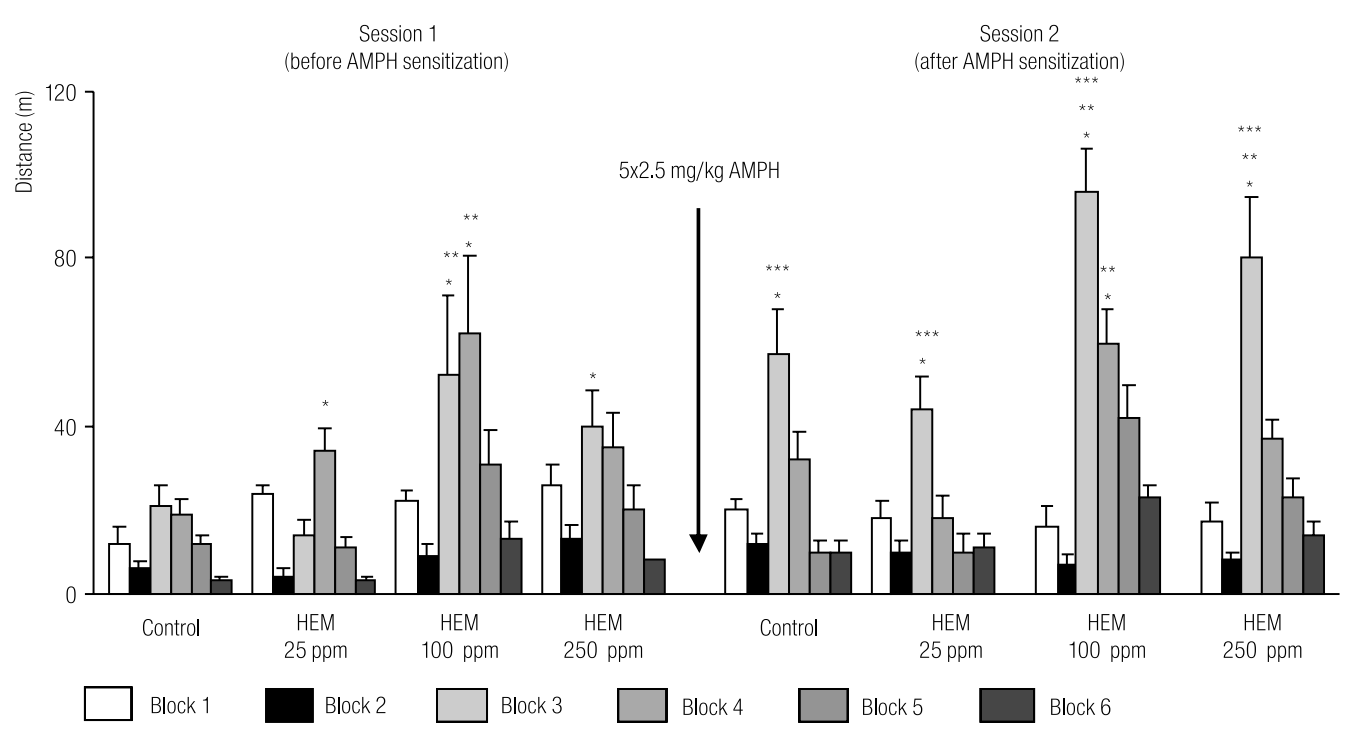

Block 1 - control (preinjection) activity, block 2 - activity after the SAL injection, blocks 3, 4, 5 and 6 - activity during successive 30 min sections after AMPH $(0.5 \mathrm{mg} / \mathrm{kg})$ injection.

ANOVA: group effects: $\mathrm{F}(3.24)=9.80 ; \mathrm{P}=0.0002$; session effects: $\mathrm{F}(1.24)=34.22 ; \mathrm{P}=0.0000$; interaction: $\mathrm{F}(3.24)=20.64 ; \mathrm{P}=0.0000$.

$* \mathrm{P}<0.05$ - compared to post SAL measurement.

** $\mathrm{P}<0.05-$ compared to control 0 in the same session.

*** $\mathrm{P}<0.05$ - compared to corresponding measure before sensitization.

The bars represent mean values and SEM of the ambulatory activity (distance in metres) in successive 30 min blocks in the rats exposed

to hemimellitene on the locomotor response to AMPH challenge before (session 1) and 14 days after (session 2) a repeated

$(2.5 \mathrm{mg} / \mathrm{kg}, 1 /$ day $\times 5$ days $)$ AMPH treatment.

Fig. 1. Diagrams illustrating the effect of prior exposure to hemimellitene on the locomotor response to AMPH challenge before (session 1) and 14 days after (session 2$)$ a repeated $(2.5 \mathrm{mg} / \mathrm{kg}, 1 /$ day $\times 5$ days) AMPH treatment.

of the pharmacological challenge). Additional comparisons between groups were made using summarised data from blocks 3, 4, 5, and 6. Data concerning each solvent were analysed separately. Statistical assessment was performed with the use of a two- way ANOVA for repeated measurements (groups x successive measurements). Detailed comparisons were performed with Tukey test. Differences were regarded as significant when the probability of the null hypothesis was less than $5 \%(\mathrm{p}<0.05)$.

\section{RESULTS}

\section{Body weight}

At the first and the last day of the exposure the mean body weight of rats - all groups combined was $322.4 \pm 5.22 \mathrm{~g}$ and $343.1 \pm 9.70 \mathrm{~g}$, respectively. The ANOVA (groups $\times$ measurements) showed that only the measurement factor was significant: $\mathrm{F}(1.49)=146.94$, $\mathrm{p}<0.0001$.

\section{Sensitivity to AMPH and susceptibility to psychostimulant sensitization after the solvent exposure}

The typical pattern of behaviour during testing with the adopted test procedure was as follows. In block 1 the motoric activity, horizontal (locomotion) and vertical (rears), was related with the exploration of the cage environment. During the first several minutes this activity was intense but soon declined and the animal assumed a sitting posture in a corner of the cage. It rose again for a short time (5-10 $\mathrm{min})$ in block 2, i.e. after the SAL injection. A marked increase in activity occurred after the AMPH $(0.5 \mathrm{mg} / \mathrm{kg})$ challenge. The psychostimulant effect was most evident in the first 30 min after AMPH (block 3 ), and was still notable in the next $30 \mathrm{~min}$ (block 4). In the second 


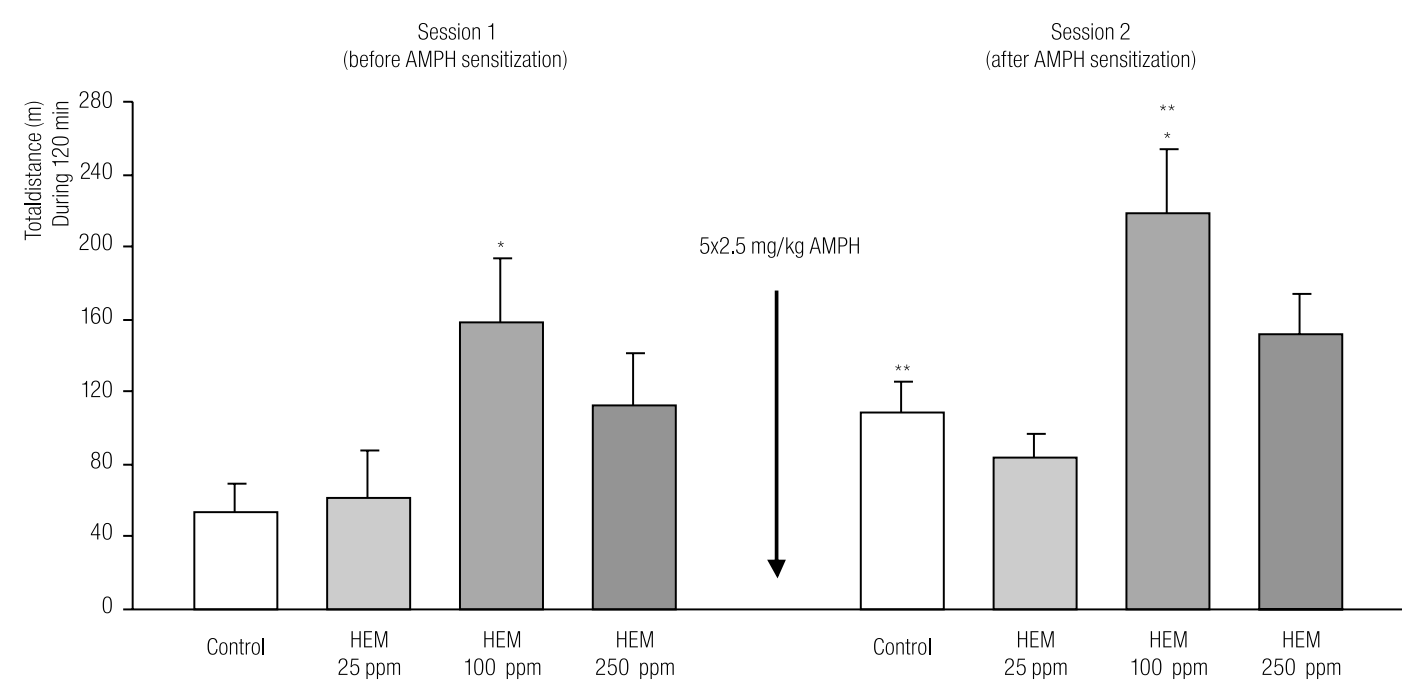

${ }^{*} \mathrm{P}<0.05$ - compared to control. ${ }^{* *} \mathrm{P}<0.05$ - compared to corresponding measure before sensitization.

Bars represent mean values and SEM of the cumulated locomotor activity (distance in metres) during the 2-hour measurement following AMPH $(0.5 \mathrm{mg} / \mathrm{kg})$ challenge.

Fig. 2. Diagrams illustrating the effect of prior exposure to hemimellitene on the locomotor response to AMPH challenge before (session 1) and 14 days after (session 2) a repeated AMPH treatment ( $2.5 \mathrm{mg} / \mathrm{kg}, 1 /$ day $\times 5$ days).

hour after AMPH (blocks 5 and 6), the activity resembled that from block 1 and 2 . The above pattern of the procedure-related changes in activity was best seen in the measures of locomotion (distance and the number of ambulation episodes). It was also present in the measurements of the vertical activity (number of rears), but in this case the between-subject variability was very high, what made results of statistical comparisons unreliable. Therefore, results concerning the vertical activity will not be presented below. Omitted are also data concerning the number of ambulation episodes. The analysis of this measure provided results resembling those produced by the analysis of the distance. To show the effects of AMPH challenge clearly, the data for blocks 3, 4, 5 and 6 were pooled and subjected to a separate analysis.

\section{Hemimellitene}

Figures 1 and 2 illustrate the effects of exposure to hemimellitene. Figure 1 gives results of all measurements (30 min blocks). Fig. 2 shows pooled postAMPH measurements (block 3, 4, 5 and 6). With regard to the data presented in Figure 1, the analysis revealed no significant differences between groups in block 1 (preinjection measurement) and block 2 (postSAL measurement). Differences between groups appeared after AMPH challenge and concerned block 3 and 4 . In session 1, the distance walked by rats of the HM 100 group in these blocks was significantly longer than that walked by rats of the control group. Also in the HM 250 group, the postAMPH locomotion was apparently more intense than in the control group, but the difference appeared insignificant statistically. In session 2, in all groups, the distance walked in block 3 was significantly longer compared to that in block 3 of session 1, indicating an increased sensitivity to AMPH after the repeated AMPH treatment. In groups HM 100, however, this increase was the highest; in this group the distance walked in block 3 , as well as the summed distance from blocks $3,4,5$ and 6 , in session 2 were significantly longer than in the control group in the same session.

\section{Pseudocumene}

In all groups exposed to PS, the spontaneous locomotor activity in block 1 of session 1 was increased compared to the control group, although the difference was significant only for the PS 250 group. In block 2 there were no differences between groups. Significant differences appeared in block 3. In session 1, the AMPH challenge resulted in increased locomotor activity in the control group and 


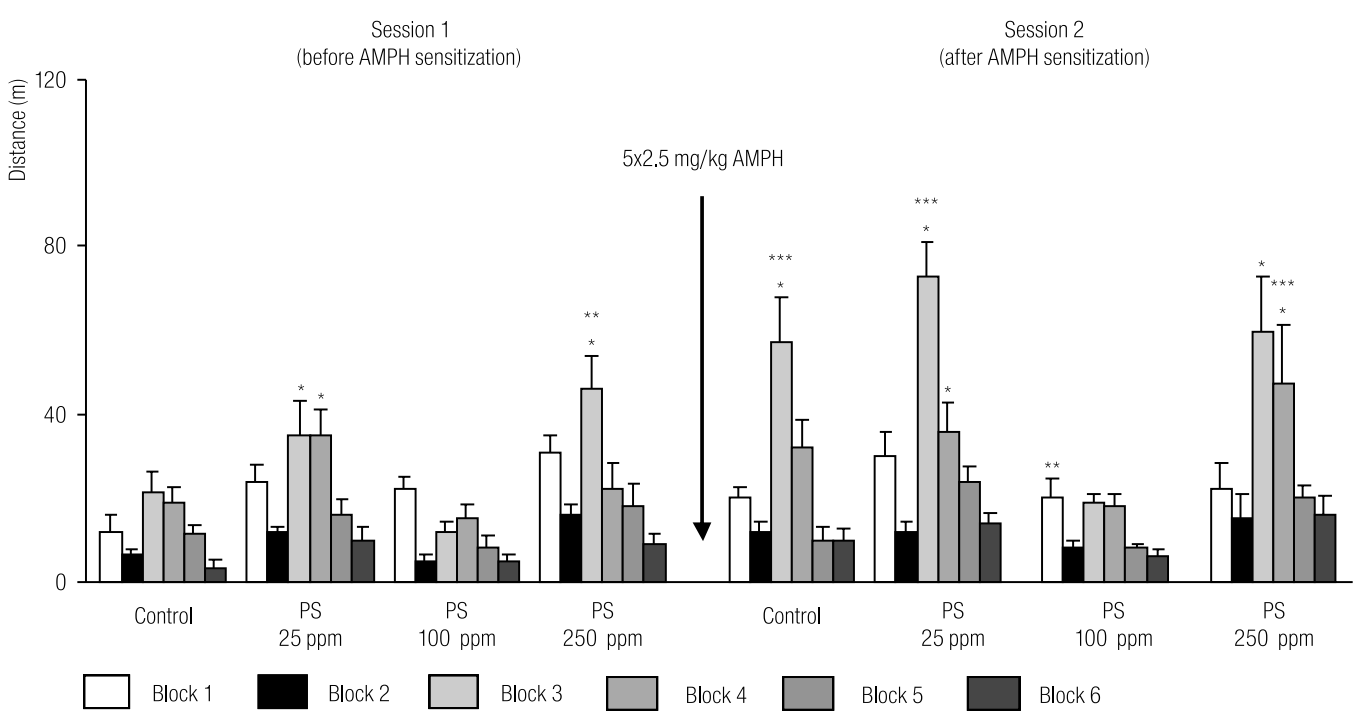

ANOVA: group effects: $\mathrm{F}(3.25)=8.90 ; \mathrm{P}=0.004$. Session effects: $\mathrm{F}(1.25)=30.91 ; \mathrm{P}=0.0000$. Interaction: $\mathrm{F}(3.25)=29.48 ; \mathrm{P}=0.0000$.

$* \mathrm{P}<0.05$ - compared to post SAL measurement.

** $\mathrm{P}<0.05$ - compared to control 0 in the same session.

*** $\mathrm{P}<0.05$ - compared to corresponding measure before sensitization.

The bars represent mean values and SEM of the ambulatory activity (distance in metres) in successive 30 min blocks.

Remaining denotations as in Figure 1.

Fig. 3. Diagrams illustrating the effect of prior exposure to pseudocumene on the locomotor response to AMPH challenge before (session 1$)$ and 14 days after (session 2) a repeated $(2.5 \mathrm{mg} / \mathrm{kg}, 1 /$ day $\times 5$ days) AMPH treatment.

in the PS 25 and PS 250 groups. In both those exposed groups, this increase was more pronounced than in the control group, although only in case of the PS 250 group the difference was significant statistically. Surprisingly, in group PS 100, the locomotor activity in block 1 of session 1 was evidently lower than in the control group and significantly lower that in the PS 25 and PS 250 groups. In session 2, i.e. after the sensitization procedure, the locomotor response to AMPH in group PS 25 and PS 250 was augmented to a similar degree as in the control group. In group PS 100, however, the sensitization procedure resulted in no change in the response to the AMPH challenge.

\section{DISCUSION}

Results of the present study may be summarized as follows:

a) A low-level 4-week inhalation exposure to TMB isomers, hemimellitene or pseudocumene, results in alterations in the rat's behavioural sensitivity to an
AMPH challenge and susceptibility to become sensitized by a repeated AMPH treatment;

b) The alterations are detectable several weeks after the exposure, which means that they are long-lasting and not related directly to the presence of the solvent or its metabolites in the organism;

c) In case of each solvent, the exposure-effect relationship is nonlinear. Of the three concentrations used: 25, 100 and $250 \mathrm{ppm}$, the concentration of 100 ppm appeared to be the most effective;

d) The alterations induced by exposure to $100 \mathrm{ppm}$ hemimellitene or pseudocumene go in opposite directions: exposure to HM results in increased, and exposure to PS in decreased behavioural sensitivity to AMPH and susceptibility to sensitisation by a repeated AMPH treatment.

The fact that the TMB exposures resulted in altered sensitivity to AMPH and susceptibility to AMPH sensitisation is not surprising. As mentioned in the Introduction, results of earlier experiments suggested long-lasting changes in the CNS functional state after a similar TMB 


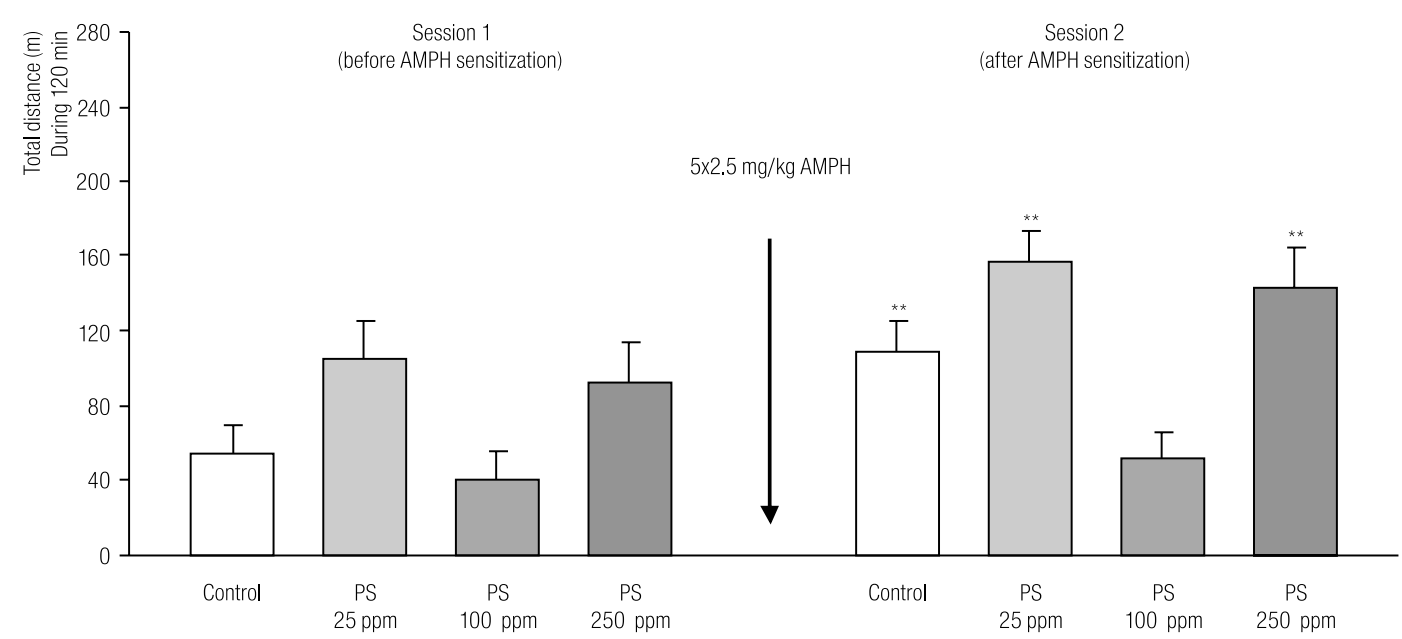

${ }^{*} \mathrm{P}<0.05$ - compared to control. ${ }^{*} \mathrm{P}<0.05$ - compared to corresponding measure before sensitization.

Bars represent mean values and SEM of the cumulated locomotor activity (distance in metres) during the 2-hour measurement following AMPH $(0.5 \mathrm{mg} / \mathrm{kg})$ challenge.

Fig. 4. Diagrams illustrating the effect of prior exposure to pseudocumene on the locomotor response to AMPH challenge before (session 1) and 14 days after (session 2) a repeated AMPH treatment ( $2.5 \mathrm{mg} / \mathrm{kg}, 1 /$ day $\times 5$ days).

exposure [21,22]. In those experiments, the passive avoidance test appeared to be the most sensitive in detection of the exposure effects. The HEM as well as the PS exposed rats were apparently deficient in the performance of this test. Based on the results of the remaining test, this deficit was interpreted as an impairment in the inhibition of the motoric response in situations of threat. Deficits of similar type are produced by dopaminergic agonists [25] and, according to some authors, the dopaminergic system is particularly vulnerable to the toxic activity of solvents [15]. Therefore, we think it reasonable to assume that the behavioural alterations produced by the TMB exposure were due mainly to some functional changes within the dopaminergic system. AMPH is an indirect dopaminergic agonist [26] and the dopaminergic system plays a key role in the sensitisation to psychostimulants $[14,27]$. Thus, the changes in the responsiveness to AMPH and propensity to AMPH sensitisation found in the present experiments may confirm the suggestion that TMB exposures produce longlasting changes in the functional state of the dopaminergic system. In the earlier experiments mentioned above, the concentration-effect relationship was nonlinear; the behavioural alterations were most pronounced in rats exposed to $100 \mathrm{ppm}$ of PS or HM. Therefore, also the fact that the $100 \mathrm{ppm}$ concentration appeared most effective in the present experiments is not surprising. Nonlinearity in the concentration/dose effect relationship is common in case of the acute effects of solvents - psychomotor arousal at low and depression at high concentrations but at concentrations much higher than those used in the present study. Some data concerning toluene, however, indicate that, depending on the experimental endpoints, the nonlinearity may be observed even at concentrations close to the adopted hygienic standards [28]. The most surprising in the present experiment is the apparently opposing character of the effects produced by PS and HM. This is in disagreement with the previous studies where the behavioural effects of exposure to these solvents did not differ qualitatively. A tentative conclusion from the present results is that, at some exposure levels (conditions), exposure to HM may result in an augmented behavioural sensitivity to AMPH and increased susceptibility of the experimental animals to become sensitised by a repeated AMPH treatment. At the same exposure conditions, exposure to PS results in a decreased sensitivity to AMPH and susceptibility to sensitization by a repeated AMPH treatment. If the behavioural sensitisation to AMPH (and other psychostimulants) underlies some aspects of drug addiction, then the present results might indicate that, at least at certain exposure levels, exposure to HM increases 
and exposure to PS reduces the propensity for developing drug dependence.

It is also quite likely, however, that the contradistinction of the effects produced by exposure to HM and PS is apparent or limited to the behavioural aspect only. First of all, it is worth mentioning that the character of the open-field behavioural response to an AMPH challenge depends on many factors, including the type of the prior exposure. Weeks after an intermittent or even single administration of AMPH, the behavioural response to AMPH challenge is augmented [29]. Exposure to an organophosphorus pesticide, on the other hand, results, weeks later, in behavioural hyposensitivity to an AMPH challenge [24,30]. In both cases, however, the humoral response to the AMPH challenge, i.e. the increase in the plasma corticosterone, is augmented (personal information). It may indicate that humoral sensitization and behavioural sensitization may remain unrelated, depending on the type of the inducing stimulus. Another conjecture worth considering as the possible cause of different behavioural effects produced by exposure to PS or HM is different stressfulness of these substances for the rat. (This conjecture assumes that the difference in the action between PS and HM is quantitative rather than qualitative.) There is no doubt that inhaling TMBs, similarly as other aromatic hydrocarbons, may provoke stress response, especially in species with highly developed sense of smell [31-33]. Some years ago, Antelman et al. showed that the changes developing after exposure to a stressor (termed by Antelman as Time-Dependent Sensitization - TDS) may, depending on the strength of the stressor, proceed in opposite directions: increased or decreased sensitivity to the inducing stressor as well as to other stressors $[34,35]$. It is likely that, owing to differences in the spatial configuration of the methyl groups, the PS odour is being perceived by the rat as more unpleasant or alarming, and therefore more stressful, than the HM odour (or vice versa). Thus, the opposing character of the behavioural effects of exposure to PS or HM could result from differences in stressfulness between these two solvents. If the above conjecture is true, then one may expect that, at some concentration, the effect of exposure to PS will be the same as effects of exposure to $100 \mathrm{ppm}$ of HM and vice versa. However, checking whether this conjecture is true would require another experiment employing much broader range of concentrations that that used in the present one.

Although the results presented here provide no answer to the question about the nature of the HM and PS effects, they show quite clearly that exposure to the substances may result in altered sensitivity to AMPH and/or influence the development of the long-term adaptive changes induced by a repeated administration of the psychostimulant. It needs to be emphasized that the effective concentrations for these effects are relatively low (are likely to occur during work with technical mixtures containing TMBs). Finally, it is worth stating that, thanks to the efforts of some research groups, the list of industrial chemicals able to induce behavioural sensitisation (or TDS) continues to be extended. To date, apart from toluene [10,12,36], sensitization to psychostimulants was described after exposure to formaldehyde [37,38]. It is suspected that this characteristic is also shared by some pesticides [7] and heavy metals [5].

\section{ACKNOWLEDGEMENTS}

This study was performed as part of a scientific project supported by the Nofer Institute of Occupational Medicine (IMP 1.19). The skilful technical assistance of Mr. Krzysztof Mader is gratefully acknowledged.

\section{REFERENCES}

1. Robinson TE, Berridge KC. The psychology and neurobiology of addiction: an incentive-sensitization view. Addiction 2000;95 Suppl 2:S91-117.

2. Robinson TE, Berridge KC. The neural basis of drug craving: an incentive-sensitization theory of addiction. Brain Res Rev 1993;18(3):247-91.

3. Robinson TE, Berridge KC. The incentive sensitization theory of addiction: some current issues [review]. Philos Trans R Soc Lond B Biol Sci 2008;363(1507):3137-46.

4. Meaney MJ, Brake W, Gratton A. Environmental regulation of the development of mesolimbic dopamine systems: 
neurobiological mechanism for vulnerability to drug abuse. Psychoneuroendocrinology 2002;27(1-2):127-38.

5. Nation JR, Smith KR, Bratton GR. Early developmental lead exposure increases sensitivity to cocaine in a self-administration paradigm. Pharmacol Biochem Behav 2004;77(1):127-35.

6. Sorg BA, Tschirgi ML, Swindell S, Chen L, Fang J. Repeated formaldehyde effects in an animal model for multiple chemical sensitivity. Ann N Y Acad Sci 2001;933: 57-67.

7. Gilbert ME. Repeated exposure to lindane leads to behavioral sensitization and facilitates electrical kindling. Neurotoxicol Teratol 1995;17:131-41.

8. Von Euler G, Ogren SO, Li XM, Fuxe K, Gustafsson JA. Persistent effects of subchronic toluene exposure on spatial learning and memory, dopamine-mediated locomotor activity and dopamine D2 agonist binding in the rat. Toxicology 1993;77(3):223-32.

9. Von Euler G, Ogren SO, Eneroth P, Fuxe K, Gustafsson JA. Persistent effects of 80 ppm toluene on dopamine-regulated locomotor activity and prolactin secretion in the male rat. Neurotoxicology 1994;15(3):621-4.

10. Beyer CE, Stafford D, LeSage MG, Glowa JR, Steketee JD. Repeated exposure to inhaled toluene induces behavioral and neurochemical cross-sensitization to cocaine in rats. Psychopharmacology 2001;154(2):198-204.

11. Funada M, Sato M, Zhou X, Kanai H, Wada K. Neuroadaptative mechanism from development of dependence on volatile organic solvents. Jpn J Psychopharmacol 2005;25(1):1-9 [in Japanese].

12. Funada M, Aoo N, Wada K. Neurochemical mechanisms for development of psychological dependence on volatile organic solvents [review]. Jpn J Psychopharmacol 2008;28(1):7-10 [in Japanese].

13. Bowen SE, Batis JC, Paez-Martinez N, Cruz SL. The last decade of solvent research in animal models of abuse: mechanistic and behavioral studies. Neurotoxicol Teratol 2006;28(6):63647.

14. Vanderschuren LJ, Kalivas PW. Alterations in dopaminergic and glutamatergic transmission in the induction and expression of behavioral sensitization: a critical review of preclinical studies. Psychopharmacology 2000;151(2-3):99-120.

15. Mutti A, Smargiassi A. Selective vulnerability of dopaminergic systems to industrial chemicals: risk assessment of related neuroendocrine changes. Toxicol Ind Health 1998;14 (1-2):311-23.

16. Gralewicz S, Dyzma M. Organic solvents and the dopaminergic system [review]. Int J Occup Med Environ Health 2005;18(2):103-13.

17. Ikeda M. Public health problems of organic solvents. Toxicol Lett 1992;64-65:191-201.

18. Wesołowski W, Gromiec JP. Occupational exposure in Polish paint and lacquer industry. Int J Occup Med Environ Health 1997;10(1):79-88.

19. The American Conference of Governmental Industrial Hygienists. Threshold Limit Values for Chemical Substances and Physical Agents and Biological Exposure Indices. Cincinnati: ACGIH; 2008. p. 59.

20. Jakubowski M. Toluene: Documentation of the occupational exposure limit values. Princ Methods Assessing Working Environ 2007;53:131-58.

21. Gralewicz S, Wiaderna D, Tomas T, Rydzyński K. Behavioral changes following 4-week inhalation exposure to pseudocumene (1,2,4-trimethylbenzene) in the rat. Neurotoxicol Teratol 1997;19(4):327-33.

22. Wiaderna D, Gralewicz S, Tomas T. Behavioral changes following a four-week inhalation exposure to hemimellitene (1,2,3-trimethylbenzene) in rats. Int J Occup Med Environ Health 1998;11(4):319-34.

23. Antelman SM, Eichler AJ, Black CA, Kocan D. Interchangeability of stress and amphetamine in sensitization. Science 1980;207(4428):329-31.

24. Lutz P, Wiaderna D, Gralewicz S, Kur B. Exposure to chlorphenvinphos, an organophosphate incesticide, prevents from behavioral sensitization to amphetamine. Int J Occup Med Environ Health 2006;19:132-41.

25. Jackson DM, Westlind-Danielsson A. Dopamine receptors: molecular biology, biochemistry and behavioral aspects [review]. Pharmacol Ther 1994;64(2):291-370.

26. Berman SM, Kuczenski R, McCracken JT, London ED. Potential adverse effects of amphetamine treatment on brain and behavior: a review. Mol Psychiatry 2009;14(2):123-42.

27. Vezina P. Sensitization of midbrain dopamine neuron reactivity and the self-administration of psychomotor stimulant drugs. Neurosci Biobehav Rev 2004;27(8):827-39. 
28. Cintra A, Andbjer B, Finnman UB, Hagman M, Agnati LF, Höglund $\mathrm{G}$, et al. Subacute toluene exposure increases $D A$ dysfunction in the 6-OH dopamine lesioned nigrostriatal dopaminergic system of the rat. Neurosci Lett 1996;217(1):61-5.

29. Vanderschuren LJ, Schmidt ED, De Vries TJ, Van Moorsel CA, Tilders FJ, Schoffelmeer AN. A single exposure to amphetamine is sufficient to induce long-term behavioral, neuroendocrine and neurochemical sensitization in rats. J Neurosci 1999;19(21):9579-86.

30. Gralewicz S, Lutz P, Szymczak W. Hyposensitivity to amphetamine following exposure to chlorphenvinphos. Protection by amphetamine pretreatment. Acta Neurobiol Exp 2000;60(2):203-8.

31. Morrow BA, Redmond AJ, Roth RH, Elsworth JD. The predator odor, TMT, displays a unique, stress-like pattern of dopaminergic and endocrinological activation in the rat. Brain Res 2000;864(1):146-51.

32. Vanderwolf CH, Zibrowski EM, Wakarchuk D. The ability of various chemicals to elicit olfactory beta-waves in the pyriform cortex of meadow voles (Microtus pennsylvanicus) and laboratory rats (Rattus norvegicus). Brain Res 2002;924(2):151-8.
33. Zibrowski EM, Hoh TE, Vanderwolf $\mathrm{CH}$. Fast wave activity in the rat rhinencephalon: elicitation by the odors of phytochemicals, organic solvents and a rodent predator. Brain Res 1998;800(2):207-15.

34. Antelman SM, Caggiula AR, Kocan D, Knopf S, Meyer D, Edwards DJ, et al. One experience with ,lower” or ,higher” intensity stressors, respectively, enhances or diminishes responsiveness to haloperidol weeks later: implications for understanding drug variability. Brain Res 1991;566(1-2):276-83.

35. Antelman SM, Soares JC, Gershon S. Time-dependent sensitization - possible implications for clinical psychopharmacology. Behav Pharmacol 1997;6-7:505-14.

36. Rogers WR, Miller CS, Bunegin L. A rat model of neurobehavioral sensitization to toluene. Toxicol Ind Health 1999;15:356-69.

37. Sorg BA, Bailie TM, Tschirgi ML, Li N, Wu WR. Exposure to repeated low-level formaldehyde in rats increases basal corticosterone levels and enhances the corticosterone response to subsequent formaldehyde. Brain Res 2001;898:314-20.

38. Sorg BA, Hochstatter T. Behavioral sensitization after repeated formaldehyde exposure in rats. Toxicol Ind Health 1999;15:346-55. 